\title{
Agricultura Familiar: Caracterização de unidades familiares de municípios da Costa Oeste Paranaense.
}

\author{
Family Farming: Characterization of family units of municipalities of the West \\ Coast of Parana.
}

\author{
Valdir Serafim $\operatorname{Jr}^{1}(*)$ \\ Adriana Maria de Grandi² \\ Fabiola Graciele Besen³ \\ Tércio Vieira de Araújo ${ }^{4}$
}

\section{Resumo}

O presente trabalho apresenta a situação atual das unidades de agricultura familiar de municípios da Região Costa Oeste do Paraná, com base em diagnósticos levantados pela ADEOP - Agência de Desenvolvimento do Extremo Oeste do Paraná, entre os anos de 2010 e 2012. Inicialmente, caracterizou-se os municípios, na sequência, apresentou-se o tamanho das áreas das unidades familiares, seguido pelas análises de seus titulares em termos de gestão, seus membros, mão de obra e renda, finalizando com as caracterizações intrínsecas relacionadas às pessoas residentes nestas unidades. Estas análises tiveram como propósito identificar fatores que comprometem o desenvolvimento rural e fornecer resultados práticos através de informações que possam ser utilizadas para uma melhor compreensão deste meio, garantindo a inclusão social destes agricultores e a possibilidade de permanência no campo. Concluiu-se que as relações socioeconômicas potencializadas pelas empresas e Estado, nas últimas décadas, nos eixos de desenvolvimento onde se encontram esses municípios, os vários processos emancipatórios que impulsionaram a proximidade entre rural e urbano e os processos históricos de partilha e herança, contribuíram para o êxodo rural, envelhecimento e masculinização nas unidades familiares estudadas, devido ao poder atrativo pela oferta de oportunidades para os jovens agricultores.

Palavras chave: Agricultura familiar, desenvolvimento rural, relações socioeconômicas.

1 Doutorando Extensão inovadora e Desenvolvimento rural sustentável - Universidade Estadual do Oeste do Paraná, UNIOESTE, Brasil; professor assistente da UNIOESTE - Universidade Estadual do Oeste do Paraná, Campus Foz do Iguaçu - Pr, Coordenador do Curso de Ciências Contábeis (2015 a 2019), atua como docente o curso de Ciências Contábeis na disciplina de Contabilidade Geral II; Endereço: Universidade Estadual do Oeste do Paraná. Avenida Tarquínio Joslin dos Santos, 1300, Loteamento Universitário das Américas. CEP: 85870650 - Foz do Iguaçu, PR - Brasil E-Mail: jr_valdir@hotmail.com (*) Autor para correspondências.

2 Dra.; Engenharia Agrícola; Universidade Federal de Viçosa, UFV, Brasil; Professora Associado A da Universidade Estadual do Oeste do Paraná; Endereço: Universidade Estadual do Oeste do Paraná, Centro de Ciências Agrárias. Pernambuco, 1777. CEP: 85960-000 - Marechal Candido Rondon, PR - Brasil E-Mail: adrianadegrandi@gmail.com

3 Doutoranda Extensão Inovadora e Desenvolvimento Rural Sustentável; Universidade Estadual do Oeste do Paraná, UNIOESTE, Brasil; Professora Assistente no Curso de Ciências Contábeis na Unioeste - Universidade Estadual do Oeste do Paraná - Campus de Foz do Iguaçu, ministra a disciplina de Contabilidade e análise de custos e coordena o Estágio Supervisionado; Endereço: Universidade Estadual do Oeste do Paraná. Avenida Tarquínio Joslin dos Santos, 1300, Loteamento Universitário das Américas. CEP: 85870650 E-Mail: fabiolagracielebesen@gmail.com

$4 \quad$ MSc.; Extensão Inovadora e Desenvolvimento Rural Sustentável; Universidade Estadual do Oeste do Paraná, UNIOESTE, Brasil; Professor Assistente no Curso de Ciências Contábeis das disciplinas de Pesquisa em Contabilidade e Contabilidade Societária pela UNIOESTE - Campus de Foz do Iguaçu; Endereço: Universidade Estadual do Oeste do Paraná. Avenida Tarquínio Joslin dos Santos, Loteamento Universitário das Américas. CEP: 85870650 - Foz do Iguaçu, PR - Brasil E-Mail: professortercio@hotmail.com

\begin{tabular}{llllll}
\hline Ambiência & Guarapuava (PR) & v.14 n.2 & p. $401-422$ & Maio/Ago 2018 & ISSN $1808-0251$
\end{tabular}




\section{Abstract}

This study presents the current situation of the family agriculture units of municipalities in the West Coast Region of Paraná, based on the diagnoses raised by ADEOP (Parana State Development Agency) between 2010 and 2012. Initially, the municipalities were characterized; after this the size of the areas of family units were presented; followed by the analyzes of their owners in terms of management, their members, labor and income; and finally the intrinsic characterizations related to the people who reside in these units. These analyzes aimed to identify factors that compromise rural development and to provide practical results through information that can be used to better understand this environment, ensuring the social inclusion of these farmers and the possibility of permanence in the field. It was concluded that the socio-economic relations enhanced by the companies and state throughout the last decades, in the axes of development where these municipalities are located, the emancipatory processes that promoted the proximity between rural and urban and the historical processes of sharing and inheritance, contributed to the rural exodus, aging and masculinization in the family units studied, due to the attractive power of opportunities offered for young farmers.

Keywords: Family agriculture, rural development, socioeconomic relations.

\section{Introdução}

Vários estudos apontam as mudanças sofridas pelo rural brasileiro nas últimas décadas, principalmente em relação à agricultura familiar, dentre as quais os crescentes avanços tecnológicos que contribuem para a redução da necessidade de uso de mão de obra nas atividades agrícolas e para o agravamento de outros problemas como o empobrecimento rural, êxodo rural, entre outros.

A região Costa Oeste do Paraná, foco do presente estudo, apresenta características peculiares, primeiramente pela sua localização geográfica, na tríplice fronteira: Brasil, Paraguai e Argentina e por estar entre eixos de desenvolvimento econômico importantes entre as cidades de Foz do Iguaçu, Cascavel e Toledo. Outra característica não menos importante, são os impactos gerados pela construção da Hidrelétrica de Itaipu e a formação de seu reservatório, fato este que redesenhou geográfica e economicamente os municípios atingidos.

Como a agricultura familiar exerce papel de grande importância, seja economicamente pela produção de alimentos e geração de renda, ou socialmente pela geração de emprego e ocupação, existe a necessidade de conhecer as características locais ou em pequenas regiões, possibilitando avaliações da dimensão e evolução em que se encontram estas unidades familiares.

A partir destas considerações, delimitou-se o problema de pesquisa: Quais as características sócio produtivas das unidades de agricultura familiar dos municípios da Costa Oeste do Paraná?

O problema de pesquisa tem como objetivo geral identificar as principais características das unidades de agricultura familiar dos seis municípios objetos desse estudo com base nos dados coletados dos diagnósticos efetuados pela Agência de Desenvolvimento do Oeste do Paraná ADEOP entre os anos de 2010 a 2012, correspondentes aos atendimentos efetuados em forma de Assistência Técnica e Extensão Rural - ATER nesse período.

Atendendo ao problema de pesquisa, foram estabelecidos os objetivos específicos para se atingir o objetivo geral: a) identificar a composição produtiva das áreas das unidades familiares 
em seus respectivos municípios; b) identificar o tamanho das famílias, ocupação da mão de obra e composição das faixas de renda; e c) identificar se existe processo de envelhecimento ou masculinização do campo pelas características das pessoas residentes nas unidades familiares.

O Estado do Paraná ocupa uma área de $199.880 \mathrm{Km}^{2}$. Situado na região sul do país, é reconhecido nacionalmente como um dos maiores produtores nacionais de grãos e apresenta uma produção agrícola diversificada. Dentre as culturas mais presentes estão as relacionadas à fruticultura, à cana de açúcar, ao milho, à soja, à mandioca, ao trigo e à batata inglesa. A pecuária paranaense também é destaque na economia do Estado, compreendendo como principais a avicultura de corte, a bovinocultura de corte e leite e a suinocultura (IPARDES, 2016).

A região Oeste do Paraná, onde encontram-se os municípios objetos desse estudo, é compreendida pelas microrregiões de Foz do Iguaçu, Cascavel e Toledo. Historicamente, sua área já foi ocupada por indígenas, espanhóis e pertenceu à Capitania de São Paulo.

A partir da década de 1920, iniciou-se a migração de alemães e italianos vindos do Rio Grande do Sul e Santa Catarina para a região Oeste Paranaense. Ao se instalarem, mantiveram o modelo de ocupação de seus estados de origem, pequenas propriedades familiares rurais. Em 1930, essa migração foi impulsionada pelo governo federal brasileiro com o movimento chamado "Marcha para Oeste", com o intuito de ocupar as terras fronteiriças do interior do país (NADALIN, 2001 apud PRIORI, et al, 2012).

A região apresentava condições favoráveis para o desenvolvimento da agricultura, o que gerou grande motivação para a migração. Esse período de ocupação coincidiu com a Segunda Guerra Mundial (1939-1945), que impulsionou a ampliação de vários setores, entre eles a industrialização e a criação de uma fronteira agrícola forte para a produção de matéria prima. Nesse processo, as empresas privadas de colonização foram bem mais eficientes que o Estado, por conhecer técnicas que conseguiam gerar desenvolvimento econômico para a região colonizada, utilizando-as para o aumento de seus lucros (PRIORI, et al, 2012).

Para atrair os agricultores gaúchos e catarinenses, utilizava-se o "boca-a-boca" pelos dirigentes das companhias colonizadoras e por comerciantes da região Sul. Esse procedimento tinha o intuito de evitar a presença de aventureiros, pois os sulistas apresentavam as características julgadas necessárias para participarem deste processo, tinham conhecimento das técnicas agrícolas, possuíam recursos para a compra dos lotes, tinham descendência italiana e alemã, considerada mais evoluída na época, e isso era um ponto de diferenciação dos nortistas, que vinham de Minas Gerais e do Nordeste Brasileiro para o trabalho nas lavouras de café do Paraná (STECA e FLORES, 2002).

Priori et al (2012) cita Myskiw (2002) para identificar como as empresas planejavam a venda dos lotes, urbanos ou rurais, pois no seu contrato com o Estado, tinham que administrar as atividades relacionadas à extração de madeira, ao desenvolvimento da indústria, do comércio e à venda de terras:

Os lotes coloniais, medindo em torno de 25 hectares, formariam perímetros de área diferentes de acordo com o relevo e hidrografia. Ao redor dos núcleos populacionais foram criados lotes de 2,5 hectares, chácaras destinadas ao cultivo de hortigranjeiros. Internamente, os núcleos populacionais urbanos (vilas e cidades) seriam divididos em quarteirões, ou seja, 10.000 metros quadrados (um hectare), contando cada quarteirão com 10 lotes de 100 metros quadrados (MYSKIW, 2002, p.67). 
A partir de 1930, começou a delinear-se uma política interessada em fazer do Brasil uma grande nação. Como é um país capitalista, seguindo o modelo econômico, que visava o desenvolvimento industrial, em sua busca de acumulação, a produção energética passou a ser de vital importância para cumprir esse papel. As décadas seguintes se dedicaram a esse objetivo, e a construção da Usina Hidrelétrica de Itaipu, nesse aspecto justificava-se, pois iria abastecer o Estado de São Paulo, maior centro industrial do país (LIMA, 2006).

$\mathrm{Na}$ década de 1960, ocorreu um grande processo de urbanização no eixo rodoviário de Cascavel - Foz do Iguaçu e o aparecimento de vários núcleos urbanos, impulsionando o crescimento dos municípios de Céu Azul, Matelândia, Medianeira e São Miguel do Iguaçu (COLODEL, 1992, apud PERIS, et al, 2003).

A forma de organização da agricultura está relacionada ao modo de exploração e ao tamanho das propriedades rurais. $\mathrm{Na}$ agricultura familiar, a gerência da propriedade é feita pela própria família e o trabalho em sua maior parte também, podendo haver contratação de mão de obra esporadicamente, mantendo a atividade agrícola como a principal fonte de renda.

Sua base está relacionada com a terra, o trabalho e a família, diferenciando-a da agricultura patronal, pois este tipo de organização apresenta maiores níveis de tecnificação, investimentos, é um mercado voltado a produções em escala e agronegócio.

Há várias definições para essa categoria social. Segundo Abramovay:

A agricultura familiar é aquela em que a gestão, a propriedade e a maior parte do trabalho vêm de indivíduos que mantêm entre si laços de sangue ou de parentesco. Que esta definição não seja unânime e muitas vezes tampouco operacional é perfeitamente compreensível, já que os diferentes setores sociais e suas representações constroem categorias científicas que servirão a certas finalidades práticas: a definição de agricultura familiar, para fins de crédito, pode não ser exatamente a mesma daquela estabelecida com finalidades de quantificação estatística num estudo acadêmico. O importante é que estes três atributos básicos (gestão, propriedade e trabalho familiares) estão presentes em todas elas (ABRAMOVAY, 1997, p. 03).

A Lei 11.326/06 estabeleceu diretrizes para a formulação da Política Nacional de Agricultura Familiar e define os empreendimentos familiares rurais:

Art. $3^{\circ}$ Para os efeitos desta Lei, considera-se agricultor familiar e empreendedor familiar rural aquele que pratica atividades no meio rural, atendendo, simultaneamente, aos seguintes requisitos:

I - não detenha, a qualquer título, área maior do que 4 (quatro) módulos fiscais;

II - utilize predominantemente mão de obra da própria família nas atividades econômicas do seu estabelecimento ou empreendimento;

III - tenha renda familiar predominantemente originada de atividades econômicas vinculadas ao próprio estabelecimento ou empreendimento;

IV - dirija seu estabelecimento ou empreendimento com sua família (BRASIL, 2006, Lei no 11.326).

O Dossiê Estatístico elaborado pelo Instituto Nacional de Colonização e Reforma Agrária - INCRA e o Fundo das Nações Unidas para a Agricultura e Alimentação - FAO (1996), define a Agricultura Familiar como sendo: a) a gestão da unidade produtiva e os investimentos nela realizados são feitos por indivíduos que mantém entre si laços de sangue ou de casamento; b) a maior parte do trabalho é igualmente fornecida pelos membros da família; e, c) a propriedade 
dos meios de produção (embora nem sempre da terra) pertence à família e é em seu interior que se realiza sua transmissão em caso de falecimento ou de aposentadoria dos responsáveis pela unidade produtiva (SILVA e JESUS, 2010).

Um dos primeiros aspectos a ser considerado para caracterizar esse espaço refere-se ao êxodo rural. De acordo com Feijó (2010), no final do século XX, o Brasil apresentou uma crescente e expressiva taxa de urbanização, tornando-se um país esmagadoramente urbano, pois o passado no campo estava relacionado com uma vida de miséria e atraso.

A má distribuição de terras, poucos com muito e muitos com pouco, a falta de assistência pública, a falta de crédito e as dificuldades de escoamento da produção aos centros consumidores deixavam mais evidente a dificuldade de permanência no campo; na contramão existia o processo de industrialização, o crescimento dos setores de comércio e serviços nos centros urbanos conferiam às cidades um grande poder de atratividade, que eram difundidos pelos meios de comunicação, criando a expectativa de uma vida mais glamorosa nas cidades (FEIJÓ, 2010).

Conforme a Tabela 1, no decorrer das décadas, o êxodo rural foi aumentando, pois os trabalhadores foram perdendo espaço para as máquinas e implementos agrícolas, e os agricultores, que não conseguiam acompanhar esse processo de modernização, foram tornando-se ineficazes e deixavam o meio rural para os centros urbanos.

\section{Tabela 1 - Distribuição percentual da população brasileira urbana e rural}

\begin{tabular}{cccccccccc}
\hline $\begin{array}{c}\text { Grupos/ } \\
\text { ano }\end{array}$ & $\mathbf{1 9 4 0}$ & $\mathbf{1 9 5 0}$ & $\mathbf{1 9 6 0}$ & $\mathbf{1 9 7 0}$ & $\mathbf{1 9 8 0}$ & $\mathbf{1 9 9 1}$ & $\mathbf{1 9 9 6}$ & $\mathbf{2 0 0 0}$ & $\mathbf{2 0 1 0}$ \\
\hline Urbano & 31,1 & 36,2 & 45,4 & 55,9 & 67,6 & 75,5 & 78,4 & 81,2 & 84,4 \\
Rural & 68,8 & 62,8 & 54,6 & 44,1 & 32,4 & 24,5 & 21,6 & 18,8 & 15,6 \\
\hline
\end{tabular}

Fonte: IBGE, 2016, adaptado pelos autores.

Outro fator que contribuiu para esta mudança de estrutura populacional que está ocorrendo entre o urbano e o rural é a saída dos jovens, pois os atrativos para sua permanência no campo são menores que as oportunidades geradas no contexto urbano, seja pela renda, pela quantidade de atrativos e lazer, pelo acesso ao ensino, pela dificuldade e pela imagem negativa do trabalho agrícola, contribuindo para o envelhecimento e masculinização do meio rural (GODOY, et al, 2012).

Este processo de êxodo dos jovens é tratado por Brummer, et al (2005), como um fator de impedimento para o desenvolvimento da agricultura familiar, pois a sua continuidade está ligada com a tendência que estes jovens, filhos de agricultores familiares, apresentam em relação à sucessão de seus pais.

As últimas décadas demonstram as grandes transformações que o espaço agrícola vem sofrendo em termos populacionais. Um fator preponderante para o início dessa transformação foi o desenvolvimento industrial a partir de 1960, impulsionando a economia e a modernização da agricultura, dando início aos grandes processos de urbanização e as dificuldades de permanência no campo dos agricultores menos capitalizados (BUAINAIN, et al, 2014). 


\section{Material e métodos}

Esta pesquisa caracteriza-se como um estudo exploratório descritivo das informações extraídas do banco de dados e relatórios do "Pronaf Sustentável na BP3", trabalho conduzido e desenvolvido pela ADEOP - Agência de Desenvolvimento do Extremo Oeste do Paraná, qualificada como OSCIP - Organização da Sociedade Civil de Interesse Público, junto ao Ministério da Justiça, inserida no Parque Tecnológico de Itaipu - PTI. O trabalho foi desenvolvido durante os anos de 2010 a 2012 em conjunto com a Itaipu Binacional e FPTI - Fundação Parque Tecnológico Itaipu.

O método de pesquisa classifica-se como dedutivo, considerando que as informações essenciais necessárias para o desenvolvimento do estudo encontram-se explícitas nos diagnósticos efetuados pela ADEOP nas unidades familiares, analisados para as respectivas conclusões.

A pesquisa teve uma abordagem quantitativa, que para Fonseca (2002), está relacionada com a possibilidade de quantificação dos resultados, como se estes representassem um retrato real da população que é alvo da pesquisa, concentra-se na objetividade e é influenciada pelo positivismo, considerando que a compreensão da realidade somente poderá ser feita com a análise dos dados brutos.

Este estudo investigou 625 unidades familiares estabelecidas dentro dos municípios de Itaipulândia, Missal, Santa Helena, Santa Terezinha de Itaipu, São Miguel do Iguaçu e Medianeira, sendo o principal motivo desse agrupamento a proximidade geográfica, características climáticas e tipos de solo similares, semelhanças no IDH e sistemas produtivos, atendidos em forma de ATER - Assistência Técnica e Extensão Rural pela ADEOP entre os anos de 2010 e 2012, sendo estas unidades compostas por agricultores familiares tradicionais ou assentados de reforma agrária, que apresentavam requisitos legais para serem enquadrados como Agricultura Familiar e não estavam recebendo assistência técnica de nenhum outro órgão durante este período.

Em seu desenvolvimento, foi necessário contato com a ADEOP e Itaipu Binacional para autorização e acesso às informações, estas obtidas através dos diagnósticos das unidades familiares levantados no período de ATER. Para melhor definição, estes dados foram separados em dois grupos, o primeiro grupo se definiu por uma visão macro, categorizou-se as unidades familiares pela sua localização geográfica, pelos tamanhos de área, pelos responsáveis da unidade, pela quantidade de membros da família e mão de obra utilizada. No segundo grupo, buscou-se identificar a individualidade dos componentes dessas unidades familiares, buscando características sociais desses agricultores e de seus familiares.

Os dados secundários foram extraídos dos diagnósticos das unidades familiares efetuados pela ADEOP e tabulados. Em seguida, foram inseridos em software de gerenciamento estatístico próprio para proceder suas análises quantitativas.

\section{Resultados e discussão}

A Tabela 2 traz a caracterização dos municípios quanto a sua colonização, identificou-se a predominância de alemães e italianos, oriundos dos estados do Rio Grande do Sul e Santa Catarina, sendo que, no município de Santa Terezinha de Itaipu, relata-se também a presença de colonizadores do norte do Paraná. 
Quanto aos índices de urbanização, a maior concentração encontra-se nos municípios que fazem parte do eixo Foz do Iguaçu x Cascavel, ligados pela rodovia federal BR 277. A maior taxa de urbanização está no município de STI - Santa Terezinha de Itaipu com 90,38\%, seguido por MED - Medianeira, 89,41\% e SMI - São Miguel do Iguaçu com 63,97\%. Os demais municípios apresentam grau de urbanização similares, estão situados no eixo Foz do Iguaçu x Guaíra, ligados pela rodovia estadual PR 495, e o maior índice de urbanização está no município de SH - Santa Helena com 53,76\%, seguido por ITP - Itaipulândia 52,53\% e MIS - Missal com 51,75\%. Em relação à qualidade de vida humana, características sociais, culturais e políticas, o IDH dos municípios apresentam valores comparados a um médio desenvolvimento.

\section{Tabela 2 - Caracterização dos municípios}

\begin{tabular}{|c|c|c|c|c|c|c|c|c|}
\hline Município & $\begin{array}{l}\text { Área } \\
\text { Km2 }\end{array}$ & $\begin{array}{l}\text { Colonização } \\
\text { predominante }\end{array}$ & Emancipação & $\begin{array}{c}\text { População } \\
\text { censitária } \\
2010\end{array}$ & $\begin{array}{c}\text { População } \\
\text { censitária } \\
\text { urbana }\end{array}$ & $\begin{array}{c}\text { População } \\
\text { censitária } \\
\text { rural }\end{array}$ & $\begin{array}{c}\text { Urbano } \\
\%\end{array}$ & $\begin{array}{l}\text { IDH } \\
2010\end{array}$ \\
\hline ITP & 332,317 & $\begin{array}{l}\text { Alemã, Italiana } \\
\quad(\mathrm{RS}, \mathrm{SC})\end{array}$ & 1992 (SMI) & $9.026,00$ & $4.741,00$ & $4.285,00$ & 52,53 & 0,738 \\
\hline MED & 325,167 & $\begin{array}{l}\text { Alemã, Italiana } \\
\quad(\mathrm{RS}, \mathrm{SC})\end{array}$ & 1960 & $41.817,00$ & $37.390,00$ & $4.427,00$ & 89,41 & 0,763 \\
\hline MIS & 323,042 & $\begin{array}{l}\text { Alemã, Italiana } \\
\quad(\mathrm{RS}, \mathrm{SC})\end{array}$ & 1981 (MED) & $10.474,00$ & $5.420,00$ & $5.054,00$ & 51,75 & 0,711 \\
\hline $\mathrm{SH}$ & 759,123 & $\begin{array}{l}\text { Alemã, Italiana } \\
\quad(\mathrm{RS}, \mathrm{SC})\end{array}$ & 1967 & $23.413,00$ & $12.586,00$ & $10.827,00$ & 53,76 & 0,744 \\
\hline STI & 267,491 & $\begin{array}{c}\text { Alemã, Italiana } \\
\text { (RS, SC, PR) }\end{array}$ & $1982(\mathrm{FI})$ & $20.841,00$ & $18.837,00$ & $2.004,00$ & 90,38 & 0,738 \\
\hline SMI & 848,669 & $\begin{array}{l}\text { Alemã, italiana } \\
\quad(\mathrm{RS}, \mathrm{SC})\end{array}$ & 1961 (MED) & $25.769,00$ & $16.485,00$ & $9.284,00$ & 63,97 & 0,704 \\
\hline
\end{tabular}

Fonte: IPARDES, 2016, adaptado pelos autores.

Além desses aspectos, os eixos dos quais os municípios fazem parte influenciam diretamente no seu desenvolvimento, o que contribui para o êxodo rural, pelas oportunidades de trabalho no meio urbano, mais atraentes aos jovens que percebem perspectivas de melhoria nas condições de vida que não encontram facilmente na agricultura familiar tradicional.

Segundo Caramaro e Abramovay (2014), as regiões sul e sudeste vivenciam hoje um processo de migração bem menor do que ocorreu em seus processos históricos, questionando se as condições atuais apresentadas pelo meio rural possuem a capacidade de contribuir para uma integração econômica e emancipação social de sua população. A ideia conservadora de "fixar o homem no campo" fica desamparada quando se verifica que o meio rural cada vez mais se relaciona com as cidades, restando saber se a relação será participativa e construtiva ou promoverá a fragmentação do tecido social existente no meio rural.

No Gráfico 1, verificou-se as taxas de crescimento populacional, o crescimento urbano evidencia-se crescente em todos os municípios, porém em termos de população rural, houve um pequeno crescimento de 0,14\% em Santa Helena e um expressivo crescimento de 3,36\% em Itaipulândia. Especificamente nesse município o aumento pode estar caracterizado pela dificuldade de limitar o rural e urbano, pois nele existem várias comunidades com estilo de vida urbana, porém não consideradas como distritos, caso das comunidades de Caramuru, Jacutinga e Santa Inês, sendo necessário avaliar se este crescimento da população rural seja na verdade um crescimento de população urbana pelas características de distribuição da população. 
Nos demais municípios, evidencia-se um decréscimo, Medianeira, -0,34\%, em Missal de $-0,77 \%$, em Santa Terezinha de Itaipu de -0,32\% e São Miguel do Iguaçu de -0,91\%, sendo que nesses municípios existe a grande influência de centros maiores, a proximidade de 24 quilômetros entre os municípios de Santa Terezinha de Itaipu e Foz do Iguaçu e a expansão das atividades agroindústrias nos demais atraem cada vez mais a juventude rural, fazendo com que a sucessão dos pais pelos filhos fique comprometida nas propriedades, limitando o desenvolvimento da agricultura familiar.

\section{Gráfico 1 - Taxa de crescimento populacional Urbano e Rural}

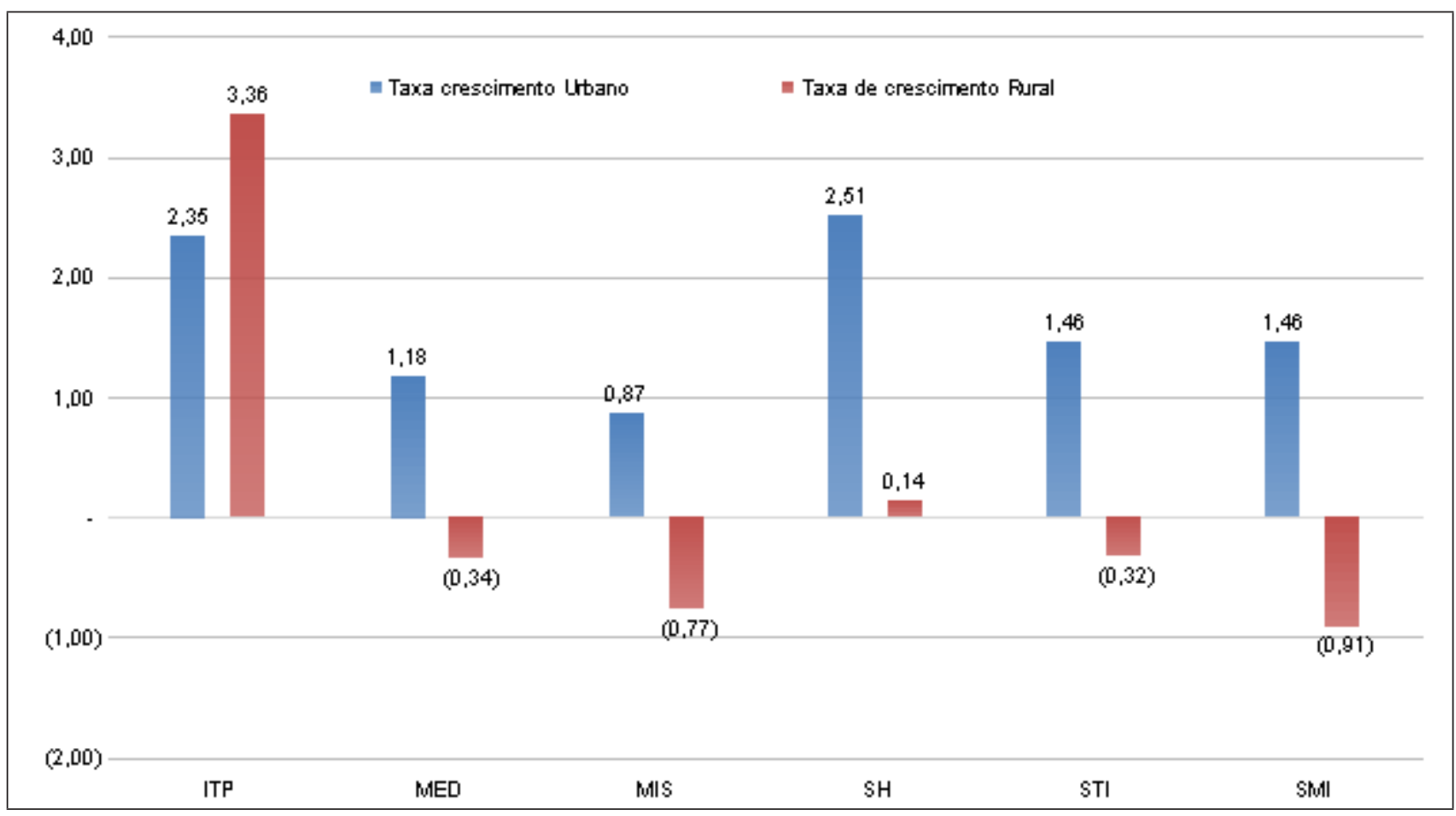

Fonte: IPARDES, 2016, adaptado pelos autores.

Wanderley (2000) constata que o meio rural corresponde ao entorno das cidades, nele predominam as paisagens naturais e os usos relacionados à terra pela produção agrícola ou mesmo aos espaços improdutivos, consequentemente refere-se a ele como sendo periferia das cidades, onde a vida de sua população depende diretamente dos centros urbanos para o acesso a médicos, bancos, poder judiciário e até mesmo a Igreja. Assim, quanto mais precárias forem as condições das localidades rurais, maior será a relação com o urbano, para suprir suas necessidades cotidianas locais, acarretando muitas vezes que os agricultores façam a opção de residir nas cidades.

Pelas características dos municípios estudados, predominantemente pequenos, verifica-se uma forte ligação do rural com o urbano. Essa proximidade é confirmada pelas suas respectivas localizações geográficas, pois os municípios que se apresentam no eixo Foz do Iguaçu x Cascavel, além de estarem entre dois centros urbanos maiores, oferecem oportunidades à população local e de seu entorno, contribuindo para o aumento de urbanização e diminuição de população rural. 


\section{Caracterização das unidades familiares}

Baseado na semelhança dos processos de colonização dos municípios estudados, que preliminarmente comercializaram lotes de 2,5 hectares próximos aos polos populacionais, e lotes coloniais de 25 hectares que estavam geograficamente mais afastados, evidenciou-se na pesquisa que as unidades familiares destes municípios se concentram em pequenas propriedades.

De acordo com Carneiro (2001), em sua pesquisa "Herança e Gênero entre Agricultores Familiares", os padrões de transmissão patrimonial acompanham as transformações econômicas e sociais sofridas pelos agricultores familiares nas regiões estudadas. Observa-se um desligamento entre família e propriedade, ocasionando a perda da identificação da terra como atividade agrícola, sendo uma das maiores mudanças contemporâneas nas práticas de partilha de herança, eternizando a situação dos migrantes, pois os novos núcleos familiares criados pelo casamento vão para diferentes lugares e direções em busca de novas terras e oportunidades.

A terra assume caráter de bem ou mercadoria, o valor histórico ou tradição não se impõe a qualquer outro, ocasionando a fragmentação excessiva das propriedades pelas práticas de partilha ou para atender a demanda de mercado pela mudança nas formas de utilização do solo (CARNEIRO, 2001).

A Tabela 3 demonstra a atual realidade das unidades familiares estudadas em relação ao tamanho de suas propriedades em seus respectivos municípios.

Pelos resultados da pesquisa, identificou-se uma menor quantidade de unidades familiares nos municípios de Santa Terezinha de Itaipu, com 41 unidades, correspondendo a 6,6\% do universo pesquisado e o município de Medianeira, com 73 unidades, com participação de 11,7\%, contribuindo para essa análise a influência do grau de urbanização destes dois municípios, de $90,38 \%$ e $89,41 \%$ respectivamente, e que apresentaram decréscimo na população rural conforme os dados apresentados.

No município de Santa Helena, foram levantados dados de 86 Unidades familiares, e uma característica desse município é a presença de ATER que já atendia parte das unidades, sendo que essas unidades correspondem a $13,8 \%$ do total.

Com o maior número de unidades familiares estudadas estão os municípios de Itaipulândia, 118 unidades familiares, Missal com 117 unidades familiares e São Miguel do Iguaçu com 190 unidades familiares, com as participações respectivas de 18,9\%, 18,7\% e 30,4\% do total, sendo que São Miguel do Iguaçu apresenta área de assentamento de reforma agrária, contribuindo para um aumento expressivo de unidades familiares. 


\section{Tabela 3 - Localização e tamanho das propriedades por municípios}

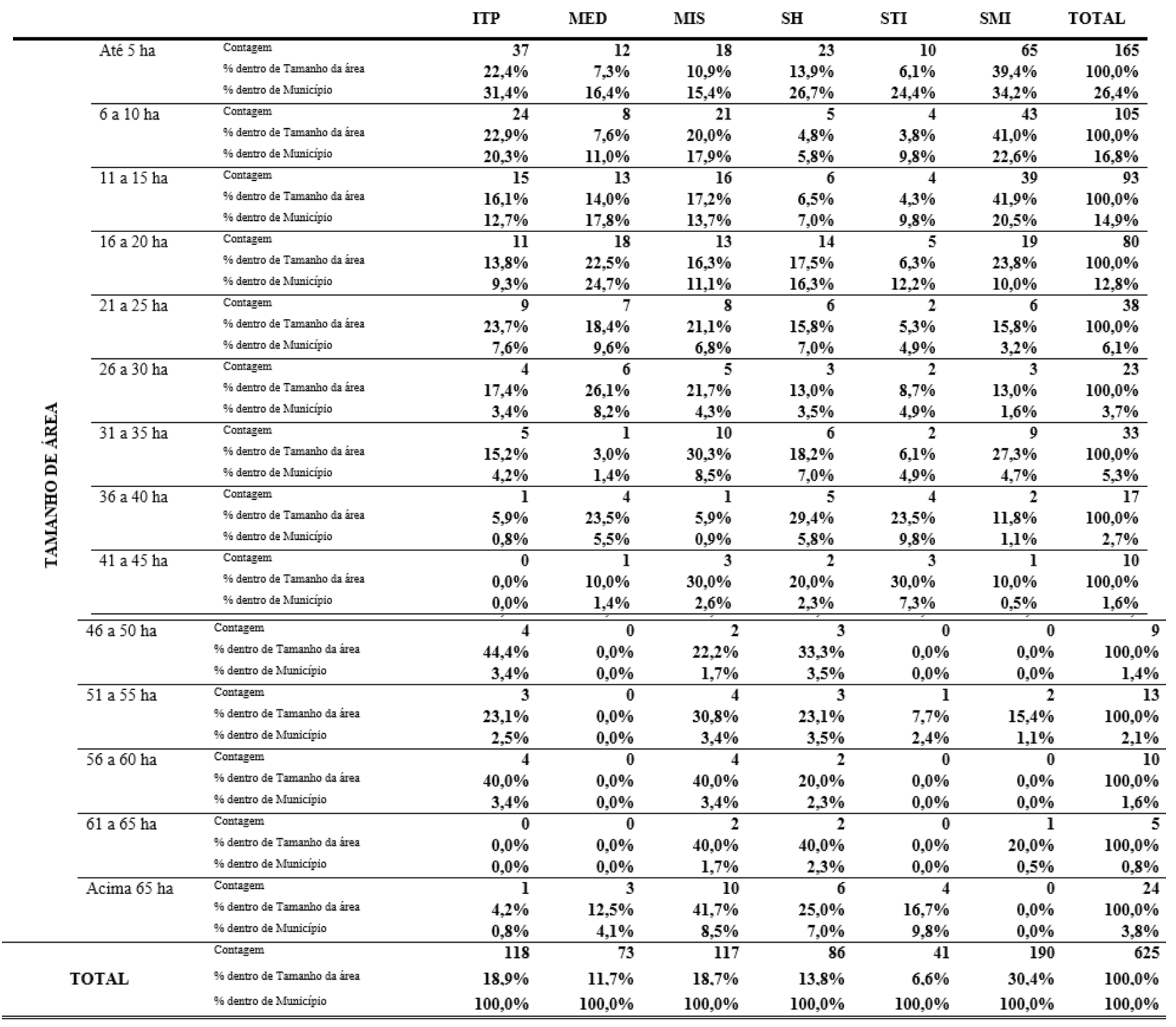

Fonte: ADEOP, 2012, adaptado pelos autores.

O tamanho da área é fator condicionante para a inclusão das propriedades em determinadas cadeias produtivas, a sustentabilidade da propriedade fica relacionada com sua localização econômica e a capacidade de investimento por parte dos agricultores familiares, estes que são exemplos da má distribuição fundiária do Brasil, sendo em números expressivos proprietários de áreas menores que 5 ha, colaborando para exploração sustentável dessas propriedades (BUAINAIN, et al, 2003).

Nos municípios estudados, $26,4 \%$ dos estabelecimentos familiares têm menos de 5 ha, $44,5 \%$ tem entre 6 a 20 ha e 20,8\% tem entre 21 a 50 ha. Os agricultores familiares com área superior a 50 ha limitadas aos 4 módulos fiscais que na região estudada corresponde a 72 ha, representam apenas $8,3 \%$ dos estabelecimentos, demonstrando a grande concentração de pequenas áreas. 
A decorrência dessa concentração de pequenas áreas pode estar relacionada ao processo de partilha nas famílias, pois se observado o período de colonização da região, entre 1950 e 1960, os agricultores que compõem essas unidades já representam a segunda e terceira geração, além de ser prática cultural e histórica a questão da sucessão das propriedades como herança. Outro fato ocorrido na região também foi o processo migratório para o centro oeste brasileiro até meados de 1980.

$\mathrm{Na}$ Tabela 4 foi identificada a categoria dos titulares das unidades familiares, sendo que 10,6\% correspondem a agricultor familiar assentado pela reforma agrária. Essa categoria está dividida em relação à área da propriedade da seguinte maneira: 9,1\% de até 5 hectares, 36,4\% de 6 a 10 hectares, $37,9 \%$ de 11 a 15 hectares,13,6\% de 16 a 20 hectares e 3\% de 21 a 25 hectares. $\mathrm{Na}$ categoria de agricultor familiar tradicional, correspondente a 559 unidades, a concentração de 28,4\% na área de até 5 hectares é predominante, provavelmente reflexo das sucessões familiares já comentadas anteriormente.

Considerando que o espaço rural não é homogêneo, Wanderley (2000) relata a importância de criação de tipologias que indiquem os principais modelos de espaços rurais e dentro de suas sugestões, contribuem para esta pesquisa duas hipóteses levantadas. A primeira hipótese é relacionada a um modelo rural com agricultura familiar no centro de uma vida social intensa, a qual por seu dinamismo depende de fatores que favoreçam a permanência no meio rural, com perspectivas de produção e comercialização, garantindo um nível de renda adequado, gerando ocupação para alguns membros da família e pluriatividade para outros.

A segunda hipótese, indica um modelo partindo da hipótese de retorno a vida rural pelos assentamentos de reforma agrária, integrado por trabalhadores rurais ou pequenos produtores anteriormente expulsos do campo, os quais mesmo com dificuldades e tensões, aprendem ou reaprendem a organizar a produção, combinando-as com demais atividades, agrícolas ou não, considerando que os assentamentos são povoados agrícolas que se refazem (WANDERLEY, 2000). 


\section{Tabela 4 - Tamanho de área pela categoria do titular}

\begin{tabular}{|c|c|c|c|c|c|}
\hline & & & \multicolumn{2}{|c|}{ Categoria do titular } & \multirow{2}{*}{ TOTAL } \\
\hline & & & Familiar Tradicional & Familiar Assentado & \\
\hline \multirow{56}{*}{ 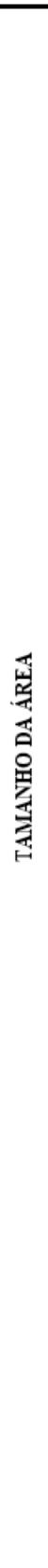 } & \multirow{4}{*}{ Ate 5 ha } & Contagem & 159 & 6 & 165 \\
\hline & & $\%$ dentro de Tamanho da área & $96,4 \%$ & $3,6 \%$ & \\
\hline & & $\%$ dentro de Categoria do titular & $28,4 \%$ & $9,1 \%$ & \\
\hline & & $\%$ do total & $25,4 \%$ & $1,0 \%$ & $26,4 \%$ \\
\hline & \multirow{4}{*}{6 a 10 ha } & Contagem & 82 & 24 & 106 \\
\hline & & \% dentro de Tamanho da área & $77,4 \%$ & $22,6 \%$ & \\
\hline & & $\%$ dentro de Categoria do titular & $14,7 \%$ & $36,4 \%$ & \\
\hline & & $\%$ do total & $13,1 \%$ & $3,8 \%$ & $17,0 \%$ \\
\hline & \multirow{4}{*}{11 a 15 ha } & Contagem & 68 & 25 & 93 \\
\hline & & \% dentro de Tamanho da área & $73,1 \%$ & $26,9 \%$ & \\
\hline & & $\%$ dentro de Categoria do titular & $12,2 \%$ & $37,9 \%$ & \\
\hline & & $\%$ do total & $10,9 \%$ & $4,0 \%$ & $14,9 \%$ \\
\hline & \multirow{4}{*}{16 a 20 ha } & Contagem & 71 & 9 & 80 \\
\hline & & $\%$ dentro de Tamanho da área & $88,8 \%$ & $11,3 \%$ & \\
\hline & & $\%$ dentro de Categoria do titular & $12,7 \%$ & $13,6 \%$ & \\
\hline & & $\%$ do total & $11,4 \%$ & $1,4 \%$ & $12,8 \%$ \\
\hline & \multirow{4}{*}{21 a 25 ha } & Contagem & 36 & 2 & 38 \\
\hline & & $\%$ dentro de Tamanho da área & $94,7 \%$ & $5,3 \%$ & 50 \\
\hline & & $\%$ dentro de Categoria do titular & $6,4 \%$ & $3,0 \%$ & \\
\hline & & $\%$ do total & $5,8 \%$ &, $3 \%$ & $6,1 \%$ \\
\hline & \multirow{4}{*}{26 a 30 ha } & Contagem & 23 & 0 & 23 \\
\hline & & $\%$ dentro de Tamanho da área & $100,0 \%$ & $0,0 \%$ & \\
\hline & & $\%$ dentro de Categoria do titular & $4,1 \%$ & $0,0 \%$ & \\
\hline & & $\%$ do total & $3,7 \%$ & $0,0 \%$ & $3,7 \%$ \\
\hline & \multirow{4}{*}{31 a 35 ha } & Contagem & 33 & 0 & 33 \\
\hline & & $\%$ dentro de Tamanho da área & $100,0 \%$ & $0,0 \%$ & \\
\hline & & $\%$ dentro de Categoria do titular & $5,9 \%$ & $0,0 \%$ & \\
\hline & & $\%$ do total & $5,3 \%$ & $0,0 \%$ & $5,3 \%$ \\
\hline & \multirow{4}{*}{36 a 40 ha } & Contagem & 16 & 0 & 16 \\
\hline & & \% dentro de Tamanho da área & $100,0 \%$ & $0,0 \%$ & \\
\hline & & $\%$ dentro de Categoria do titular & $2,9 \%$ & $0,0 \%$ & \\
\hline & & $\%$ do total & $2,6 \%$ & $0,0 \%$ & $2,6 \%$ \\
\hline & \multirow{4}{*}{41 a 45 ha } & Contagem & 10 & 0 & 10 \\
\hline & & $\%$ dentro de Tamanho da área & $100,0 \%$ & $0,0 \%$ & \\
\hline & & $\%$ dentro de Categoria do titular & $1,8 \%$ & $0,0 \%$ & \\
\hline & & $\%$ do total & $1,6 \%$ & $0,0 \%$ & $1,6 \%$ \\
\hline & \multirow{4}{*}{46 a 50 ha } & Contagem & 9 & 0 & 9 \\
\hline & & $\%$ dentro de Tamanho da área & $100,0 \%$ & $0,0 \%$ & \\
\hline & & $\%$ dentro de Categoria do titular & $1,6 \%$ & $0,0 \%$ & \\
\hline & & $\%$ do total & $1,4 \%$ & $0,0 \%$ & $1,4 \%$ \\
\hline & \multirow{4}{*}{51 a 55 ha } & Contagem & 13 & 0 & 13 \\
\hline & & $\%$ dentro de Tamanho da área & $100,0 \%$ & $0,0 \%$ & \\
\hline & & $\%$ dentro de Categoria do titular & $2,3 \%$ & $0,0 \%$ & \\
\hline & & $\%$ do total & $2,1 \%$ & $0,0 \%$ & $2,1 \%$ \\
\hline & \multirow{4}{*}{56 a 60 ha } & Contagem & 10 & 0 & 10 \\
\hline & & $\%$ dentro de Tamanho da área & $100,0 \%$ & $0,0 \%$ & \\
\hline & & $\%$ dentro de Categoria do titular & $1,8 \%$ & $0,0 \%$ & \\
\hline & & $\%$ do total & $1,6 \%$ & $0,0 \%$ & $1,6 \%$ \\
\hline & \multirow{4}{*}{61 a 65 ha } & Contagem & 5 & 0 & 5 \\
\hline & & $\%$ dentro de Tamanho da área & $100,0 \%$ & $0,0 \%$ & \\
\hline & & $\%$ dentro de Categoria do titular &, $9 \%$ & $0,0 \%$ & \\
\hline & & $\%$ do total &, $8 \%$ & $0,0 \%$ &, $8 \%$ \\
\hline & & Contagem & 24 & 0 & 24 \\
\hline & & $\%$ dentro de Tamanho da área & $100,0 \%$ & $0,0 \%$ & \\
\hline & Acima de 05 ha & $\%$ dentro de Categoria do titular & $4,3 \%$ & $0,0 \%$ & \\
\hline & & $\%$ do total & $3,8 \%$ & $0,0 \%$ & $3,8 \%$ \\
\hline & TOTAL & Contagem & 559 & 66 & 625 \\
\hline & TOAL & $\%$ do total & $89,4 \%$ & $10,6 \%$ & $100,0 \%$ \\
\hline
\end{tabular}

Fonte: ADEOP, 2012, adaptado pelos autores.

Pela predominância de pequenas propriedades, seja pela categoria dos produtores familiares tradicionais ou assentados, pode-se levantar a hipótese de dificuldade de geração de renda e sustento, e nesse sentido é bem provável que a pluriatividade esteja presente nestas unidades, não somente devido ao seu tamanho de área ou a categoria de seus titulares, mas também pelos fatores econômicos regionais que exercem estímulos para outras atividades não agrícolas. 
Outra explicação para esse cenário é dada por Carneiro (1998), que diz que o trabalho extra agrícola, executado por um ou vários membros dessas unidades, oferece obtenção de renda que pode ser um complemento para garantir a permanência dos mesmos no campo. Segundo a autora, não se deve encarar esse trabalho extra agrícola como uma falência da atividade agrícola, mas pode ser um novo tipo de forma de produção familiar, diferente da chamada agricultura familiar, pois essa opção de trabalho permite que a família possa resistir a momentos de crise, sem precisar sair do meio rural.

\section{Caracterização das famílias, mão de obra e renda}

$\mathrm{Na}$ Tabela 5, identificou-se a quantidade de membros residentes nas unidades familiares, totalizando 1745 pessoas e não foram levantadas informações sobre membros da família que residem na cidade.

Constatou-se que 18,6\% das unidades apresentam somente um membro familiar residente, $29,6 \%$ dois membros, $19,4 \%$ três membros, $22,7 \%$ quatro membros e acima de quatro membros $9,8 \%$. Quanto às unidades com somente um membro, existe a influência do envelhecimento rural, onde os processos de partilha já foram consolidados, porém parte das propriedades ainda estão relacionadas aos mais velhos, estes viúvos ou viúvas. A partir desses dados pode-se inferir sobre a questão da sucessão familiar e falta de mão de obra para as atividades agropecuárias, impossibilitando muitas vezes a continuidade no campo.

Tabela 5 - Membros familiares residentes nas unidades familiares.

\begin{tabular}{|c|c|c|c|c|c|c|c|c|c|c|c|}
\hline & & & \multicolumn{8}{|c|}{ Membros da UF } & \multirow{2}{*}{ TOTAL } \\
\hline & & & 1 & 2 & 3 & 4 & 5 & 6 & 7 & 10 & \\
\hline \multirow{24}{*}{$\begin{array}{l}\text { 을 } \\
\text { 点 } \\
\text { हn }\end{array}$} & \multirow{4}{*}{ ITP } & Contagem & 12 & 37 & 33 & 25 & 9 & 1 & 0 & 1 & 118 \\
\hline & & $\%$ dentro de Município & $10,2 \%$ & $31,4 \%$ & $28,0 \%$ & $21,2 \%$ & $7,6 \%$ &, $8 \%$ & $0,0 \%$ & $.8 \%$ & $100,0 \%$ \\
\hline & & $\%$ dentro de Membros UF & $10,3 \%$ & $20,0 \%$ & $27,3 \%$ & $17,6 \%$ & $19,6 \%$ & $10,0 \%$ & $0,0 \%$ & $100,0 \%$ & $18,9 \%$ \\
\hline & & $\%$ do Total & $1,9 \%$ & $5,9 \%$ & $5,3 \%$ & $4,0 \%$ & $1,4 \%$ & $2 \%$ & $0,0 \%$ & $.2 \%$ & $18,9 \%$ \\
\hline & \multirow{4}{*}{ MED } & Contagem & 10 & 11 & 17 & 23 & 11 & 1 & 0 & 0 & 73 \\
\hline & & $\%$ dentro de Município & $13,7 \%$ & $15,1 \%$ & $23,3 \%$ & $31,5 \%$ & $15,1 \%$ & $1,4 \%$ & $0,0 \%$ & $0,0 \%$ & $100,0 \%$ \\
\hline & & $\%$ dentro de Membros UF & $8,6 \%$ & $5,9 \%$ & $14,0 \%$ & $16,2 \%$ & $23,9 \%$ & $10,0 \%$ & $0,0 \%$ & $0,0 \%$ & $11,7 \%$ \\
\hline & & $\%$ do Total & $1,6 \%$ & $1.8 \%$ & $2,7 \%$ & $3,7 \%$ & $1.8 \%$ & $2 \%$ & $0,0 \%$ & $0,0 \%$ & $11,7 \%$ \\
\hline & \multirow{4}{*}{ MIS } & Contagem & 2 & 37 & 23 & 35 & 13 & 4 & 3 & 0 & 117 \\
\hline & & $\%$ dentro de Município & $1,7 \%$ & $31,6 \%$ & $19,7 \%$ & $29,9 \%$ & $11,1 \%$ & $3,4 \%$ & $2,6 \%$ & $0,0 \%$ & $100,0 \%$ \\
\hline & & $\%$ dentro de Membros UF & $1,7 \%$ & $20,0 \%$ & $19,0 \%$ & $24,6 \%$ & $28,3 \%$ & $40,0 \%$ & $75,0 \%$ & $0,0 \%$ & $18,7 \%$ \\
\hline & & $\%$ do Total & $3 \%$ & $5,9 \%$ & $3,7 \%$ & $5,6 \%$ & $2,1 \%$ &, $6 \%$ & $5 \%$ & $0,0 \%$ & $18,7 \%$ \\
\hline & \multirow{4}{*}{ SH } & Contagem & 7 & 14 & 27 & 29 & 8 & 1 & 0 & 0 & 80 \\
\hline & & $\%$ dentro de Municipio & $8,1 \%$ & $16,3 \%$ & $31,4 \%$ & $33,7 \%$ & $9,3 \%$ & $1,2 \%$ & $0,0 \%$ & $0,0 \%$ & $100,0 \%$ \\
\hline & & $\%$ dentro de Membros UF & $6,0 \%$ & $7,6 \%$ & $22,3 \%$ & $20,4 \%$ & $17,4 \%$ & $10,0 \%$ & $0,0 \%$ & $0,0 \%$ & $13,8 \%$ \\
\hline & & $\%$ do Total & $1,1 \%$ & $2,2 \%$ & $4,3 \%$ & $4,6 \%$ & $1,3 \%$ &, $2 \%$ & $0,0 \%$ & $0,0 \%$ & $13,8 \%$ \\
\hline & \multirow{4}{*}{ STI } & Contagem & 7 & 13 & 5 & 12 & 3 & 1 & 0 & 0 & 41 \\
\hline & & $\%$ dentro de Municipio & $17,1 \%$ & $31,7 \%$ & $12,2 \%$ & $29,3 \%$ & $7,3 \%$ & $2,4 \%$ & $0,0 \%$ & $0,0 \%$ & $100,0 \%$ \\
\hline & & $\%$ dentro de Membros UF & $6,0 \%$ & $7,0 \%$ & $4,1 \%$ & $8.5 \%$ & $6,5 \%$ & $10,0 \%$ & $0,0 \%$ & $0,0 \%$ & $0,6 \%$ \\
\hline & & $\%$ do Total & $1,1 \%$ & $2,1 \%$ &, $8 \%$ & $1,9 \%$ & $5 \%$ &, $2 \%$ & $0,0 \%$ & $0,0 \%$ & $6,6 \%$ \\
\hline & \multirow{4}{*}{ SMI } & Contagem & 78 & 73 & 16 & 18 & 2 & 2 & 1 & 0 & 190 \\
\hline & & $\%$ dentro de Municipio & $41,1 \%$ & $38,4 \%$ & $8,4 \%$ & $9,5 \%$ & $1,1 \%$ & $1,1 \%$ & $5 \%$ & $0,0 \%$ & $100,0 \%$ \\
\hline & & $\%$ dentro de Membros UF & $67,2 \%$ & $39,5 \%$ & $13.2 \%$ & $12,7 \%$ & $4,3 \%$ & $20,0 \%$ & $25,0 \%$ & $0,0 \%$ & $30.4 \%$ \\
\hline & & $\%$ do Total & $12,5 \%$ & $11,7 \%$ & $2,6 \%$ & $2,9 \%$ & $3 \%$ & $3 \%$ & $2 \%$ & $0,0 \%$ & $30,4 \%$ \\
\hline & \multirow{2}{*}{ TOTAL } & Contagem & 116 & 185 & 121 & 142 & 46 & 10 & 4 & 1 & 625 \\
\hline & & $\%$ do Total & $18,6 \%$ & $29,6 \%$ & $19,4 \%$ & $22,7 \%$ & $7,4 \%$ & $1,6 \%$ &, $6 \%$ &, $2 \%$ & $100,0 \%$ \\
\hline
\end{tabular}

Fonte: ADEOP, 2012, adaptado pelos autores. 
A Tabela 6, apresenta a relação dos membros familiares com mão de obra utilizada nas unidades familiares, $79,7 \%$ dos membros trabalham nas atividades agropecuárias. Comparando a mão de obra total das unidades verificou-se que $92,1 \%$ é de origem da própria família e que somente $7,9 \%$ é contratada.

\section{Tabela 6 - Membros familiares e mão de obra}

\begin{tabular}{ccccccc}
\hline & & \multicolumn{5}{c}{ Membros familiares e mão de obra } \\
\cline { 2 - 7 } & Membros & $\begin{array}{c}\text { MO } \\
\text { total }\end{array}$ & $\begin{array}{c}\text { MO } \\
\text { Familiar }\end{array}$ & $\begin{array}{c}\text { Familiar } \\
\text { sem } \\
\text { atividade }\end{array}$ & $\begin{array}{c}\text { MO } \\
\text { Contratada }\end{array}$ & $\begin{array}{c}\text { \% } \\
\text { TOTAL }\end{array}$ \\
\hline \multirow{2}{*}{$\begin{array}{c}\text { Membros } \\
\text { e Mão de } \\
\text { obra }\end{array}$} & $\begin{array}{c}\text { Contagem } \\
\text { \% dentro de }\end{array}$ & 1745 & 1510 & 1390 & 355 & 120 \\
\cline { 2 - 7 } & $\begin{array}{c}\text { Membros } \\
\text { \% dentro de } \\
\text { MOTotal }\end{array}$ & & $79,7 \%$ & $20,3 \%$ & $100,0 \%$ \\
\hline
\end{tabular}

Fonte: ADEOP, 2012, adaptado pelos autores.

Embora o estudo tenha identificado um esvaziamento do campo e um número cada vez mais reduzido de membros que trabalham na propriedade, por causa da saída dos filhos e também pelo fato de que a mecanização diminuiu a necessidade de mão de obra no campo, os laços familiares, às vezes, permitem que essas pessoas permaneçam no campo, pois os familiares são acionados quando há necessidade de mais pessoas em algumas fases do processo de produção, mesmo que a responsabilidade da produção seja de apenas um membro da família. É chamado de "caráter familiar da produção", em que há uma necessidade coletiva de mão de obra e então são solicitados os serviços de irmãos, filhos, noras para auxiliar em determinados processos de produção, que demandam mais mão de obra (CARNEIRO, 1998).

A análise da renda bruta anual das unidades, conforme a Tabela 7 , foi dimensionada em dois grupos. Na renda do primeiro grupo formado pelos agricultores familiares tradicionais que possuem uma variabilidade na renda, enquanto $14,3 \%$ apresentam renda inferior a $\mathrm{R} \$ 5.000,00$, $45,4 \%$ entre $R \$ 5.000,00$ e inferior a $R \$ 25.000,00,24,9 \%$ entre $R \$ 25.000,00$ e inferior a $R \$$ $50.000,00$ e $15,4 \%$ com renda superior a $R \$ 50.000,00$.

O grupo dos agricultores assentados da reforma agrária não apresentaram renda anual inferior a $R \$ 5.000,00,81,8 \%$ entre $R \$ 5.000,00$ e inferior a $R \$ 25.000,00,15,2 \%$ entre $R \$$ $25.000,00$ e inferior a $\mathrm{R} \$ 50.000,00$ e somente e $3 \%$ apresentaram renda superior a $\mathrm{R} \$ 50.000,00$.

Essas informações relacionadas à renda bruta anual dos agricultores familiares, evidencia a diferenciação dentro de seu universo, enquanto parte gera uma renda que permite uma sustentabilidade da propriedade, outra parte apresenta dificuldades relacionadas à escassez de recursos, principalmente terra e capital, agravados pela falta de mão de obra familiar. 
Tabela 7 - Renda das unidades familiares pela categoria do produtor

\begin{tabular}{|c|c|c|c|c|c|c|c|c|c|}
\hline & \multicolumn{6}{|c|}{ RENDA ANUAL } & \multirow[b]{2}{*}{ TOTAL } \\
\hline & & & $\begin{array}{l}\text { Renda } \\
\text { inferior } \\
\text { a } 5.000\end{array}$ & $\begin{array}{c}\text { Renda } \\
\text { maior } \\
\text { ou igual } \\
\text { a } 5.000 \\
\text { e menor } \\
\text { que } \\
10.000\end{array}$ & $\begin{array}{c}\text { Renda } \\
\text { maior ou } \\
\text { igual a } \\
10.000 \\
\text { e menor } \\
\text { que } \\
15.000\end{array}$ & $\begin{array}{c}\text { Renda } \\
\text { maior ou } \\
\text { igual a } \\
15.000 \\
\text { e menor } \\
\text { que } \\
25.000\end{array}$ & $\begin{array}{c}\text { Renda } \\
\text { maior ou } \\
\text { igual a } \\
25.000 \mathrm{e} \\
\text { menor que } \\
50.000\end{array}$ & $\begin{array}{c}\text { Renda } \\
\text { maior } \\
\text { ou igual } \\
\text { a } 50.000\end{array}$ & \\
\hline \multirow{8}{*}{ 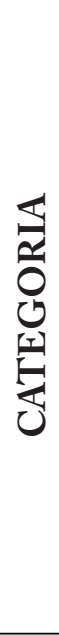 } & \multirow{4}{*}{$\begin{array}{l}\text { Agricultor } \\
\text { Familiar } \\
\text { Tradicional }\end{array}$} & Contagem & 80 & 82 & 68 & 104 & 139 & 86 & 559 \\
\hline & & $\begin{array}{c}\text { \% dentro de } \\
\text { Titular }\end{array}$ & $14,3 \%$ & $14,7 \%$ & $12,2 \%$ & $18,6 \%$ & $24,9 \%$ & $15,4 \%$ & $100,0 \%$ \\
\hline & & $\begin{array}{c}\% \text { dentro de } \\
\text { Renda }\end{array}$ & $100,0 \%$ & $87,2 \%$ & $79,1 \%$ & $81,3 \%$ & $93,3 \%$ & $97,7 \%$ & $89,4 \%$ \\
\hline & & $\%$ do Total & $12,8 \%$ & $13,1 \%$ & $10,9 \%$ & $16,6 \%$ & $22,2 \%$ & $13,8 \%$ & $89,4 \%$ \\
\hline & \multirow{4}{*}{$\begin{array}{c}\text { Agricultor } \\
\text { Assentado } \\
\text { reforma } \\
\text { agrária }\end{array}$} & Contagem & 0 & 12 & 18 & 24 & 10 & 2 & 66 \\
\hline & & $\begin{array}{c}\% \text { dentro de } \\
\text { Titular }\end{array}$ & $0,0 \%$ & $18,2 \%$ & $27,3 \%$ & $36,4 \%$ & $15,2 \%$ & $3,0 \%$ & $100,0 \%$ \\
\hline & & $\begin{array}{c}\% \text { dentro de } \\
\text { Renda }\end{array}$ & $0,0 \%$ & $12,8 \%$ & $20,9 \%$ & $18,8 \%$ & $6,7 \%$ & $2,3 \%$ & $10,6 \%$ \\
\hline & & \% do Total & $0,0 \%$ & $1,9 \%$ & $2,9 \%$ & $3,8 \%$ & $1,6 \%$ &, $3 \%$ & $10,6 \%$ \\
\hline \multirow{2}{*}{\multicolumn{2}{|c|}{$\begin{array}{l}\text { TOTAL } \\
\% \text { do Total }\end{array}$}} & Contagem & 80 & 94 & 86 & 128 & 149 & 88 & 625 \\
\hline & & $12,8 \%$ & $15,0 \%$ & $13,8 \%$ & $20,5 \%$ & $23,8 \%$ & $14,1 \%$ & $100,0 \%$ & \\
\hline
\end{tabular}

Fonte: ADEOP, 2012, adaptado pelos autores.

Esses níveis apresentados podem comprometer a capacidade de investimentos nas propriedades. Em tempos de instabilidade econômica e inflação elevada é fator inibidor para seu desenvolvimento, a descapitalização dessas unidades pela baixa renda nas atividades produtivas pode promover o esvaziamento do campo na busca de outras oportunidades não agrícolas.

A questão renda também foi relacionada com o tamanho das áreas dessas unidades familiares, conforme demonstra a Tabela 8, detectando que das 80 unidades com renda inferior a $R \$ 5.000,00$ anuais, 78,8\% apresentam área inferior a 5 hectares e 22,2\% com área de 6 a 20 hectares. Não foram encontradas unidades nesta faixa de renda com área igual ou superior a 21 hectares.

A distribuição das 94 unidades familiares com renda entre $\mathrm{R} \$ 5.000,00$ e inferior a $\mathrm{R} \$$ 10.000,00, demonstrou que 50\% possuem área de até 5 hectares, 47,8\% destas com área de 6 a 20 hectares e somente 2,2\% possuem área igual ou superior a 21 hectares. Logo pode-se inferir que há uma correlação direta de baixa renda com as pequenas propriedades

Com renda entre $R \$ 10.000,00$ e inferior a $R \$ 15.000,00$, foram encontradas 86 unidades familiares, dentre estas 19,8\% possuem área de até 5 hectares, 72,1\% com área de 6 a 20 hectares e $8,1 \%$ possuem área igual ou superior a 21 hectares; já as unidades familiares com renda entre $\mathrm{R} \$$ $15.000,00$ e inferior a $\mathrm{R} \$ 25.000,00$, em um total de 128 unidades, $14,1 \%$ possuem área de até 5 hectares, $68,8 \%$ com área de 6 a 20 hectares e 17,2\% possuem área igual ou superior a 21 hectares. 
$\mathrm{Na}$ faixa de renda entre $\mathrm{R} \$ 25.000,00$ e inferior a $\mathrm{R} \$ 50.000,00$, a pesquisa identificou 149 unidades familiares, das quais 6,7\% possuem área de até 5 hectares, 38,9\% com área de 6 a 20 hectares e área igual ou superior a 21 hectares 54,4\%, nas 88 unidades familiares restantes com renda anual superior a $\mathrm{R} \$ 50.000,00,11,4 \%$ possuem área de até 5 hectares, 10,3\% com área de 6 a 20 hectares e 78,3\% possuem área igual ou superior a 21 hectares.

\section{Tabela 8 - Renda das unidades familiares por tamanho da propriedade}

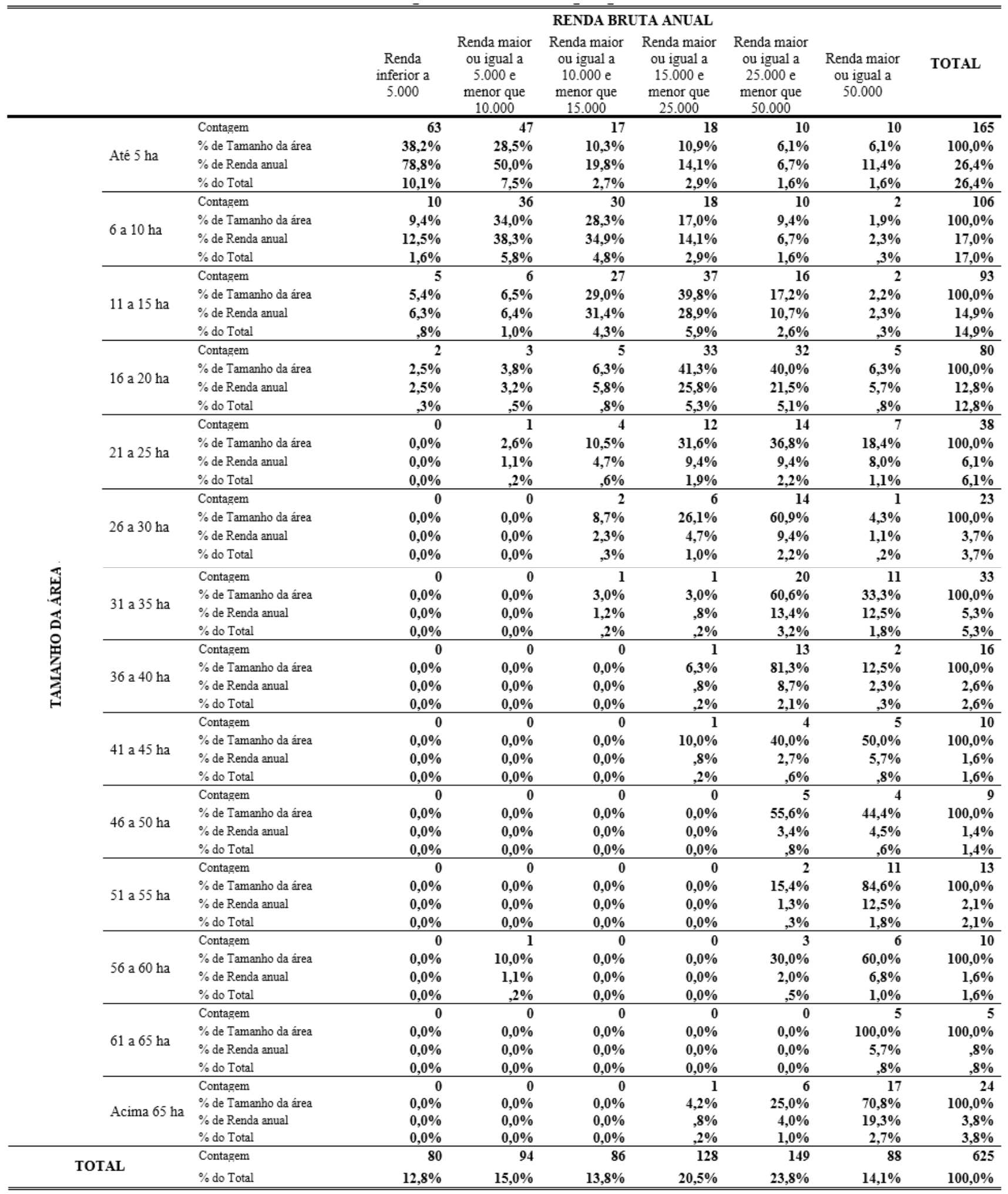

Fonte: ADEOP, 2012, adaptado pelos autores. 
Evidenciou-se na pesquisa uma relação significativa sobre tamanho da propriedade e renda, evidenciando que as menores rendas estão relacionadas em sua maioria às pequenas propriedades, e quanto mais as propriedades apresentam elevação de tamanho de área, mais elevam seu padrão de renda. Outro ponto significante foi a constatação de que as pequenas áreas também participaram em faixas de rendas mais elevadas, sendo necessário um estudo mais aprofundado em relação as suas culturas e seus respectivos mercados para identificar quais as características dessas unidades que proporcionaram esse padrão de elevação na renda.

\section{Relações de gênero nas unidades familiares}

Os dados demonstraram na Tabela 9, de maneira geral, que nos municípios do estudo, existe um processo de masculinização no campo em todas as faixas etárias, totalizando uma população masculina de $55 \%$ e feminina de $45 \%$, sendo mais evidente na faixa etária entre 20 a 29 anos, período que se conclui a maior parte dos estudos e em que se busca oportunidades de trabalho, no campo ou fora dele. Esta sobreposição masculina pode ser decorrente do fato de o homem ser, na maioria das vezes, responsável pelas atividades agrícolas e as mulheres com característica de dedicação maior aos estudos, em consequência tem maior contato com as oportunidades geradas nos ambientes não agrícolas.

Feijó (2010) relata que as cidades oferecem oportunidades que atraem a mão de obra rural, esta que foi poupada no campo pela modernização da agricultura, sendo que essas oportunidades vão se modificando ao longo do tempo, com isso alterando também o perfil dos migrantes

Na década de 1960, migravam paras as cidades pessoas na faixa etária de 40 anos, diminuindo essa faixa etária nas décadas seguintes, impulsionados pelo desejo de crescimento econômico; entre 1950 a 1980, os empregos industriais e construção civil atraiam os migrantes masculinos, sendo que as mulheres também eram empregadas em indústrias, porém tinham uma grande relação com empregos domésticos, os jovens, mais recentemente, tem buscado as cidades não necessariamente apenas por emprego, mas sim pelas possibilidades geradas em relação aos estudos que não encontram em seus locais de origem (FEIJÓ, 2010).

A masculinização também foi expressiva nas faixas de 60 a 69 anos, com 57,5\% e na faixa acima de 70 anos com 59,2\%, o que contraria que a expectativa de vida da mulher seja superior à do homem e também contribui com a informação que este processo é histórico e vem se transformando com o tempo, devendo ser levantadas as atividades desempenhadas pelas mulheres dentro dessas unidades para uma análise mais aprofundada sobre eventuais riscos.

Foi evidenciado o processo de envelhecimento nestas unidades familiares, pois $58,1 \%$ das pessoas encontram-se na faixa etária acima de 40 anos, 11,3\% entre 30 a 39 anos, 13,1\% entre 20 a 29 anos e 17,4\% menor que 20 anos. Deve-se levar em consideração que esta última faixa ainda apresenta uma dependência financeira da família, mas poderá migrar do campo para a cidade no momento de buscar emprego.

O fenômeno de envelhecimento da população no meio rural pode ser associado com o êxodo dos jovens rurais para os centros urbanos em busca de novas oportunidades relacionadas à educação e renda, ou mesmo pela mistificação do estilo de vida nas cidades, comprometendo a formação de uma nova geração de agricultores familiares. 
Tabela 9 - Faixa etária e sexo

\begin{tabular}{|c|c|c|c|c|c|}
\hline & & & \multicolumn{2}{|c|}{ SEXO } & \multirow[b]{2}{*}{ TOTAL } \\
\hline & & & Masculino & Feminino & \\
\hline \multirow{30}{*}{ 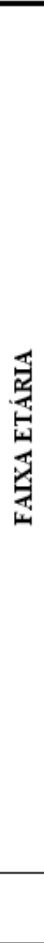 } & \multirow[t]{4}{*}{ Menor que 20 anos } & Contagem & 157 & 147 & 304 \\
\hline & & $\%$ dentro de Faixa etária & $51,6 \%$ & $48,4 \%$ & $100,0 \%$ \\
\hline & & $\%$ dentro de Sexo & $16,4 \%$ & $18,7 \%$ & $17,4 \%$ \\
\hline & & $\%$ do Total & $9,0 \%$ & $8,4 \%$ & $17,4 \%$ \\
\hline & \multirow[t]{4}{*}{ Entre 20 a 29 anos } & Contagem & 135 & 94 & 229 \\
\hline & & $\%$ dentro de Faixa etária & $59,0 \%$ & $41,0 \%$ & $100,0 \%$ \\
\hline & & $\%$ dentro de Sexo & $14,1 \%$ & $12,0 \%$ & $13,1 \%$ \\
\hline & & $\%$ do Total & $7,7 \%$ & $\mathbf{5 , 4} \%$ & $13,1 \%$ \\
\hline & \multirow[t]{4}{*}{ Entre 30 a 39 anos } & Contagem & 102 & 96 & 198 \\
\hline & & $\%$ dentro de Faixa etária & $51,5 \%$ & $48,5 \%$ & $100,0 \%$ \\
\hline & & $\%$ dentro de Sexo & $10,6 \%$ & $12,2 \%$ & $11,3 \%$ \\
\hline & & $\%$ do Total & $5,8 \%$ & $5,5 \%$ & $11,3 \%$ \\
\hline & \multirow[t]{4}{*}{ Entre 40 a 49 anos } & Contagem & 173 & 138 & 311 \\
\hline & & $\%$ dentro de Faixa etária & $55,6 \%$ & $44,4 \%$ & $100,0 \%$ \\
\hline & & $\%$ dentro de Sexo & $18,0 \%$ & $17,6 \%$ & $17,8 \%$ \\
\hline & & $\%$ do Total & $9,9 \%$ & $7,9 \%$ & $17,8 \%$ \\
\hline & \multirow[t]{4}{*}{ Entre 50 a 59 anos } & Contagem & 166 & 147 & 313 \\
\hline & & $\%$ dentro de Faixa etária & $\mathbf{5 3}, 0 \%$ & $47,0 \%$ & $100,0 \%$ \\
\hline & & $\%$ dentro de Sexo & $17,3 \%$ & $18,7 \%$ & $17,9 \%$ \\
\hline & & $\%$ do Total & $9,5 \%$ & $8,4 \%$ & $17,9 \%$ \\
\hline & \multirow[t]{4}{*}{ Entre 60 a 69 anos } & Contagem & 134 & 99 & 233 \\
\hline & & $\%$ dentro de Faixa etária & $\mathbf{5 7 , 5} \%$ & $42,5 \%$ & $100,0 \%$ \\
\hline & & $\%$ dentro de Sexo & $14,0 \%$ & $12,6 \%$ & $13,4 \%$ \\
\hline & & $\%$ do Total & $7,7 \%$ & $5,7 \%$ & $13,4 \%$ \\
\hline & \multirow[t]{4}{*}{ Maior ou igual a 70 anos } & Contagem & 93 & 64 & 157 \\
\hline & & $\%$ dentro de Faixa etária & $59,2 \%$ & $40,8 \%$ & $100,0 \%$ \\
\hline & & $\%$ dentro de Sexo & $9,7 \%$ & $8,2 \%$ & $9,0 \%$ \\
\hline & & $\%$ do Total & $5,3 \%$ & $3,7 \%$ & $9,0 \%$ \\
\hline & \multirow{2}{*}{ TOTAL } & Contagem & 960 & 785 & 1745 \\
\hline & & $\%$ do Total & $\mathbf{5 5 , 0} \%$ & $45,0 \%$ & $100,0 \%$ \\
\hline
\end{tabular}

Fonte: ADEOP, 2012, adaptado pelos autores.

Quanto ao estado civil das pessoas, constatou-se que 34,2\% são solteiros, sendo 17,1\% menores de 20 anos, 11,1\% entre 20 a 29 anos e 6\% nas demais faixas. Esses percentuais indicam concentração nas faixas que representam os jovens agricultores, porém devido ao processo de masculinização que foi evidenciado, com o passar dos anos estes índices poderão sofrer aumentos, diminuindo o número de componentes familiares, contribuindo para a elevação das taxas de envelhecimento no campo, conforme demonstra a Tabela 10.

Essas informações contribuem, novamente para uma tendência de aumento do êxodo rural, com a possibilidade desses jovens constituírem relações familiares fora do meio rural, devido as oportunidades geradas pela proximidade com o meio urbano. 
Tabela 10 - Estado civil

\begin{tabular}{|c|c|c|c|c|c|c|c|c|c|}
\hline & & & \multicolumn{5}{|c|}{ ESTADO CIVIL } & \multirow[b]{2}{*}{$\begin{array}{c}\text { Separado } \\
\text { judicialmente }\end{array}$} & \multirow[b]{2}{*}{ TOTAL } \\
\hline & & & Solteiro & Casado & Viúvo & Uniẫo estável & Diworciado & & \\
\hline \multirow{30}{*}{$\frac{\sqrt{6}}{\text { 点 }}$} & \multirow{4}{*}{$\begin{array}{l}\text { Menor que } \\
20 \text { anos }\end{array}$} & Contagem & 299 & 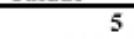 & 0 & 0 & 0 & 0 & 304 \\
\hline & & $\%$ Faixa etária & $98,4 \%$ & $1,6 \%$ & $0,0 \%$ & $0,0 \%$ & $0,0 \%$ & $0,0 \%$ & $100,0 \%$ \\
\hline & & $\%$ Estado civil & $50,2 \%$ &, $5 \%$ & $0,0 \%$ & $0,0 \%$ & $0,0 \%$ & $0,0 \%$ & $17,4 \%$ \\
\hline & & $\%$ do Total & $17,1 \%$ & $3 \%$ & $0,0 \%$ & $0,0 \%$ & $0,0 \%$ & $0,0 \%$ & $17,4 \%$ \\
\hline & \multirow{4}{*}{$\begin{array}{l}\text { Entre } 20 \text { a } 29 \\
\text { anos }\end{array}$} & Contagem & 194 & 22 & 0 & 12 & 0 & 1 & 229 \\
\hline & & \% Faika etária & $84.7 \%$ & $9.6 \%$ & $0.0 \%$ & $5.2 \%$ & $0.0 \%$ & $.4 \%$ & $100.0 \%$ \\
\hline & & $\%$ Estado civil & $32,6 \%$ & $2,2 \%$ & $\mathbf{0 , 0 \%}$ & $18,8 \%$ & $\mathbf{0 , 0} \%$ & $12,5 \%$ & $13,1 \%$ \\
\hline & & $\%$ do Total & $11.1 \%$ & $1,3 \%$ & $0.0 \%$ & $.7 \%$ & $0.0 \%$ & $.1 \%$ & $13.1 \%$ \\
\hline & \multirow{4}{*}{$\begin{array}{l}\text { Entre } 30 \text { a } 39 \\
\text { anos }\end{array}$} & Contagem & 59 & 112 & 0 & 23 & 4 & 0 & 198 \\
\hline & & \% Faixa etária & $29.8 \%$ & $56.6 \%$ & $0.0 \%$ & $11.6 \%$ & $2.0 \%$ & $0,0 \%$ & $100.0 \%$ \\
\hline & & \% Estado civil & $9,9 \%$ & $11,2 \%$ & $\mathbf{0 , 0 \%}$ & $35,9 \%$ & $21,1 \%$ & $0,0 \%$ & $11,3 \%$ \\
\hline & & $\%$ do Total & $3,4 \%$ & $6.4 \%$ & $0.0 \%$ & $1.3 \%$ & $.2 \%$ & $0,0 \%$ & $11,3 \%$ \\
\hline & \multirow{4}{*}{$\begin{array}{l}\text { Entre } 40 \text { a } 49 \\
\text { anos }\end{array}$} & Contagem & 21 & 273 & 4 & 11 & 2 & 0 & 311 \\
\hline & & \% Faixa etária & $6,8 \%$ & $87.8 \%$ & $1.3 \%$ & $3.5 \%$ & $.0 \%$ & $0,0 \%$ & $100.0 \%$ \\
\hline & & \% Estado civil & $3,5 \%$ & $27,4 \%$ & $6,7 \%$ & $17,2 \%$ & $10,5 \%$ & $0,0 \%$ & $17,8 \%$ \\
\hline & & $\%$ đo Total & $1.2 \%$ & $15,6 \%$ & $.2 \%$ & $.6 \%$ & $.1 \%$ & $0,0 \%$ & $17.8 \%$ \\
\hline & \multirow{4}{*}{$\begin{array}{l}\text { Entre } 50 \text { a } 59 \\
\text { anos }\end{array}$} & Contagem & 14 & 267 & 12 & 9 & 8 & 3 & 313 \\
\hline & & \% Faixa etária & $4.5 \%$ & $85,3 \%$ & $3.8 \%$ & $2.9 \%$ & $2.6 \%$ & $1,0 \%$ & $100.0 \%$ \\
\hline & & \% Estado civil & $2,3 \%$ & $26,8 \%$ & $20,0 \%$ & $14,1 \%$ & $42,1 \%$ & $37,5 \%$ & $17,9 \%$ \\
\hline & & $\%$ do Total & $.8 \%$ & $15,3 \%$ & $.7 \%$ & $.5 \%$ & $.5 \%$ & $.2 \%$ & $179 \%$ \\
\hline & \multirow{4}{*}{$\begin{array}{l}\text { Entre } 60 \text { a } 69 \\
\text { anos }\end{array}$} & Contagem & 3 & 202 & 14 & 8 & 3 & 3 & 233 \\
\hline & & \% Faixa etária & $1.3 \%$ & $86.7 \%$ & $6.0 \%$ & $3.4 \%$ & $1.3 \%$ & $1.3 \%$ & $100.0 \%$ \\
\hline & & $\%$ Estado civil &, $5 \%$ & $20,2 \%$ & $23,3 \%$ & $12,5 \%$ & $15,8 \%$ & $37,5 \%$ & $13,4 \%$ \\
\hline & & $\%$ do Total &, $2 \%$ & $11,6 \%$ & $8 \%$ &, $5 \%$ & $2 \%$ &, $2 \%$ & $13,4 \%$ \\
\hline & \multirow{4}{*}{$\begin{array}{l}\text { Maior ou } \\
\text { igual a } 70 \\
\text { anos }\end{array}$} & Contagem & 6 & 117 & 30 & 1 & 2 & 1 & 157 \\
\hline & & \% Faixa etária & $3,8 \%$ & $74,5 \%$ & $19,1 \%$ &, $6 \%$ & $1,3 \%$ &, $6 \%$ & $100,0 \%$ \\
\hline & & $\%$ Estado civil & $1,0 \%$ & $11,7 \%$ & $50,0 \%$ & $1,6 \%$ & $10,5 \%$ & $12,5 \%$ & $9,0 \%$ \\
\hline & & $\%$ do Total &, $3 \%$ & $6,7 \%$ & $1,7 \%$ &, $1 \%$ &, $19 \%$ &, $1 \%$ & $9,0 \%$ \\
\hline & \multirow{2}{*}{ TOTAL } & Contagem & 596 & 998 & 60 & 64 & 19 & 8 & 1745 \\
\hline & & $\%$ do Total & $34,2 \%$ & $57,2 \%$ & $3,49 \%$ & $3,7 \%$ & $1,1 \%$ &, $5 \%$ & $100,0 \%$ \\
\hline
\end{tabular}

Fonte: ADEOP, 2012, adaptado pelos autores.

A Tabela 11 apresenta de maneira geral que 95,8\% das pessoas são classificadas como brancas e as demais classificações representam $4,2 \%$ da população. Somente o município de São Miguel do Iguaçu apresentou uma pequena variação aos demais, pois dentro de suas unidades familiares, $85,5 \%$ das pessoas são classificadas como brancas, $10,5 \%$ como pardas, $2,7 \%$ como amarelas e 1,3\% como negras.

Evidencia-se ainda as características raciais dos colonizadores da região, que foram predominantemente italianos e alemães, com uma pequena distinção para o município de São Miguel do Iguaçu, que mesmo com o processo de colonização similar aos demais, acolhe unidades familiares em assentamentos de reforma agrária que receberam pessoas de outras regiões do Estado e do país. 


\section{Tabela 11 - Classificação racial}

\begin{tabular}{|c|c|c|c|c|c|c|c|c|}
\hline & & & \multicolumn{5}{|c|}{ CLASSIFICAÇĀO RACIAL } & \multirow[b]{2}{*}{ TOTAL } \\
\hline & & & Branca & Negra & Parda & Amarela & Indigena & \\
\hline \multirow{26}{*}{ 思 } & ITP & Contagem & 331 & 3 & 10 & 1 & 1 & 346 \\
\hline & & \% dentro de Município & $95,7 \%$ &, $9 \%$ & $2,9 \%$ &, $3 \%$ &, $3 \%$ & $100,0 \%$ \\
\hline & & $\%$ dentro de Classificaçāo racial & $19,8 \%$ & $33,3 \%$ & $20,0 \%$ & $7,7 \%$ & $100,0 \%$ & $19,8 \%$ \\
\hline & & $\%$ do Total & $19,0 \%$ &, $2 \%$ &, $6 \%$ &, $1 \%$ &, $1 \%$ & $19,8 \%$ \\
\hline & MED & Contagem & 236 & 0 & 0 & 0 & 0 & 236 \\
\hline & & \% dentro de Município & $100,0 \%$ & $0,0 \%$ & $0,0 \%$ & $0,0 \%$ & $0,0 \%$ & $100,0 \%$ \\
\hline & & $\%$ dentro de Classificação racial & $14,1 \%$ & $0,0 \%$ & $0,0 \%$ & $0,0 \%$ & $0,0 \%$ & $13,5 \%$ \\
\hline & & $\%$ do Total & $13,5 \%$ & $0,0 \%$ & $0,0 \%$ & $0,0 \%$ & $0,0 \%$ & $13,5 \%$ \\
\hline & MIS & Contagem & 394 & 0 & 1 & 0 & 0 & 395 \\
\hline & & \% dentro de Município & $99,7 \%$ & $0,0 \%$ &, $3 \%$ & $0,0 \%$ & $0,0 \%$ & $100,0 \%$ \\
\hline & & $\%$ dentro de Classificação racial & $23,6 \%$ & $0,0 \%$ & $2,0 \%$ & $0,0 \%$ & $0,0 \%$ & $22,6 \%$ \\
\hline & & $\%$ do Total & $22,6 \%$ & $0,0 \%$ &, $1 \%$ & $0,0 \%$ & $0,0 \%$ & $22,6 \%$ \\
\hline & $\mathrm{SH}$ & Contagem & 276 & 1 & 0 & 1 & 0 & 278 \\
\hline & & \% dentro de Municipio & $99,3 \%$ &, $4 \%$ & $0,0 \%$ &, $4 \%$ & $\mathbf{0 , 0 \%}$ & $100,0 \%$ \\
\hline & & \% dentro de Clazaificacào racial & $16.5 \%$ & $11.1 \%$ & $0.0 \%$ & $7.7 \%$ & $0.0 \%$ & $15.9 \%$ \\
\hline & & $\%$ do Total & $15,8 \%$ &, $1 \%$ & $0,0 \%$ &, $1 \%$ & $\mathbf{0 , 0 \%}$ & $15,9 \%$ \\
\hline & STI & Contagem & 116 & 0 & 0 & 1 & 0 & 117 \\
\hline & & $\%$ dentro de Municipio & $99,1 \%$ & $0,0 \%$ & $0,0 \%$ &, $9 \%$ & $\mathbf{0 , 0 \%}$ & $100,0 \%$ \\
\hline & & \% dentro de Clazaificaço racial & $6.9 \%$ & $0,0 \%$ & $0,0 \%$ & $7.7 \%$ & $0.0 \%$ & $6.7 \%$ \\
\hline & & $\%$ do Total & $6,6 \%$ & $0,0 \%$ & $0,0 \%$ &, $1 \%$ & $\mathbf{0 , 0 \%}$ & $6,7 \%$ \\
\hline & SMI & Contagem & 319 & 5 & 39 & 10 & 0 & 373 \\
\hline & & $\%$ dentro de Municipio & $85,5 \%$ & $1,3 \%$ & $10,5 \%$ & $2,7 \%$ & $\mathbf{0 , 0 \%}$ & $100,0 \%$ \\
\hline & & $\%$ dentro de Clazsificacto racial & $19.1 \%$ & $55.6 \%$ & $78,0 \%$ & $76,9 \%$ & $0.0 \%$ & $21.4 \%$ \\
\hline & & $\%$ do Total & $18,3 \%$ & $3 \%$ & $2,2 \%$ &, $6 \%$ & $\mathbf{0 , 0 \%}$ & $21,4 \%$ \\
\hline & \multirow{2}{*}{ TOTAL } & Contagem & 1672 & 9 & 50 & 13 & 1 & 1745 \\
\hline & & $\%$ do Total & $95,8 \%$ &, $5 \%$ & $2,9 \%$ &, $7 \%$ &, $1 \%$ & $100,0 \%$ \\
\hline
\end{tabular}

Fonte: ADEOP, 2012, adaptado pelos autores.

A classificação racial das pessoas, que confere características relacionadas ao processo colonizador da região, comprovou a predominância dos colonizadores da época (alemães e italianos) nessa região, pois a maioria das pessoas $(95,8 \%)$ foram classificadas como brancas.

\section{Conclusões}

O presente estudo propôs uma caracterização de unidades de agricultura familiar dos municípios da Costa Oeste do Paraná, de acordo com diagnósticos levantados pela ADEOP durante o período de 2010 a 2012. Considerando que a agricultura familiar exerce grande papel no desenvolvimento econômico pela produção de alimentos e segurança alimentar e que estes municípios apresentam características peculiares, priorizou-se as questões relacionadas às unidades familiares sem considerar seus aspectos produtivos.

Em resposta ao problema de pesquisa, a caracterização das unidades de agricultura familiar partiu da premissa de que, durante as últimas décadas as mesmas vem sofrendo transformações, seja pela própria evolução histórica da região ou por fatores sociais e econômicos; não foram abordados os sistemas produtivos, mas sim demais fatores interligados que exercem influência na garantia de permanência no campo, como o tamanho de área das propriedades, a organização das famílias e sua composição de mão de obra e renda e a relação direta dos integrantes familiares nos eventuais processos de envelhecimento e masculinização rural.

Quanto à predominância de pequenas propriedades, identificou-se que podem estar relacionadas ao processo de sucessão familiar, assim essas propriedades já estão fragmentadas devido as partilhas entre os herdeiros, comprometendo a geração de renda para uma permanência digna no meio rural. 
Identificou-se nesse primeiro momento que, pela localização geográfica das unidades, as mesmas se apresentam em eixos de desenvolvimento integrado, com forte relação com o urbano. Esta relação proporciona, principalmente aos jovens, várias outras oportunidades não relacionadas à agricultura, causando os processos de diminuição e envelhecimento das famílias e favorecendo o processo de masculinização destas unidades.

Sugere-se para futuros trabalhos a análise dos sistemas produtivos destas unidades familiares, buscando verificar suas relações com a renda e área, para que estes resultados possam ser utilizados com o propósito de fornecer subsídios para garantir a sobrevivência da agricultura familiar na região estudada.

\section{Referências bibliográficas}

ABRAMOVAY, R. Uma nova extensão rural para a agricultura familiar. In: SEMINÁRIO NACIONAL DE ASSISTÊNCIA TÉCNICA E EXTENSÃO RURAL, 1., 1997, Brasília. Anais. Brasília: PNUD, 1997.

ADEOP - Agência de Desenvolvimento do Extremo Oeste do Paraná. Pronaf Sustentável na BP3. Paraná, 2012.

BRASIL. Política Nacional da Agricultura Familiar, Lei 11.326 de 24 de julho de 2006. Em: http:/www.planalto.gov.br/ccivil_03/_ato2004-2006/2006/lei/111326.htm. Acesso em: julho de 2016.

BUAINAIN, A.M. et al. O mundo rural no Brasil do século 21 : a formação de um novo padrão agrário e agrícola / Antônio Márcio Buainain, Eliseu Alves, José Maria da Silveira, Zander Navarro, editores técnicos. - Brasília, DF : Embrapa, 2014. ,A.M. et al.Agricultura familiar e o novo mundo rural. Sociologias, v. 5, n. 10, 2003.

BRUMMER, A. et al. Gênero e agricultura familiar: projeto de jovens filhos de agricultores familiares na Região Sul do Brasil. Fazendo Gênero 8 - Corpo, violência poder. Florianópolis, 2005.

CARAMARO, A.A.; ABRAMOVAY, R. Êxodo rural, envelhecimento e masculinização no Brasil: panorama dos últimos cinquenta anos. Revista Brasileira de Estudos de População, v. 15, n. 2, p. 45-65, 2014.

CARNEIRO, M.J. Herança e gênero entre agricultores familiares. Estudos Feministas, p. 22-55, 2001. Camponeses agricultores e pluriatividade. Rio de Janeiro : Contra Capa Livraria, 1998.

FEIJÓ, R.C. Economia Agrícola e Desenvolvimento Rural. LTC, 12/2010.

FONSECA,J.J.S. Metodologia da pesquisa científica. Ceará: Universidade Estadual do Ceará, 2002.

GODOY, C.M.T. et al.Juventude Rural, envelhecimento e o papel da aposentadoria no meio rural: A realidade do município de Santa Rosa/RS. 2012.

IBGE - Instituto Brasileiro de Geografia e Estatística - CENSOS DEMOGRÁFICOS. Em: http:/www.ibge.gov.br/home/estatistica/populacao/censo2010/default.shtm. Acesso em: julho de 2016.IPARDES - Instituto Paranaense de Desenvolvimento Econômico e Social CADERNOS ESTATÍSTICOS MUNICIPAIS - PR. Em: http://www.ipardes.gov.br/index. php?pg conteudo=1\&cod conteudo=30. Acesso em: julho de 2016. 
LIMA, I.T.C. Itaipu: as faces de um mega projeto de desenvolvimento. Marechal Cândido Rondon-PR: Editora Germânica, 2006.

PERIS, A.F. (Org), et al. Estratégias de desenvolvimento regional: Região Oeste do Paraná. Cascavel: Edunioeste, 2003.

PRIORI, A., et al. História do Paraná: séculos XIX e XX. Maringá: Eduem, 2012. A história do Oeste Paranaense. pp. 75-89. ISBN 978-85-7628-587-8.

SILVA, J.R., JESUS, P. Os desafios do novo rural e as perspectivas da agricultura familiar no Brasil. Anais do V CONNEPI (Congresso Norte-Nordeste de Pesquisa e Inovação. Em: http:// congressos.ifal.edu.br/index.php/connepi/ CONNEPI2010/paper/viewFile/1407/457

STECA, L.C.; FLORES, M.D. História do Paraná do século XVI à década de 1950. $3^{\mathrm{a}}$ ed. Londrina: UEL, 2002.

WANDERLEY, M. A valorização da agricultura familiar e a reivindicação da ruralidade no Brasil. Desenvolvimento e Meio Ambiente, v. 2, 2000. 